\title{
DESENVOLVIMENTO DE UM EROSÍMETRO PARA SIMULAR O DESGASTE EROSIVO POR MEIO LAMACENTO*
}

Luiz Henrique Simões dos Reis ${ }^{1}$ Victor Pizetta David ${ }^{2}$

Pablo Altoé Amorim ${ }^{3}$ Sandro Mauro de Carvalho ${ }^{4}$

\section{Resumo}

Este trabalho estuda o fenômeno da erosão e a validação de um erosímetro. Com este propósito, as taxas de erosão, perda de massa acumulada por unidade de área e o fator de esfericidade foram medidos. Os testes foram realizados com corpos de prova de latão $360 \mathrm{CLA}$, efetuando quatro testes com durações de 5, 10, 15 e 20 horas, respectivamente. As amostras foram pesadas em uma balança de precisão antes e após os testes. O abrasivo utilizado foi a areia ABNT em uma concentração de $10 \%$ em peso. O impacto repetitivo entre as partículas abrasivas causou trincas, lascamentos e, consequentemente, a formação de partículas menores. Também foi constatado o arredondamento das partículas abrasivas. Tais fatos são a causa do decréscimo da taxa de erosão com o aumento do tempo de teste. Micrografias apresentam a degradação da superfície na parte frontal do corpo de prova devido à remoção de material. $O$ erosímetro obteve sucesso nas comparações com outros artigos.

Palavras-chave: Erosímetro; Erosão por meio lamacento; Fator de esfericidade.

\section{DEVELOPMENT OF SLURRY POT TESTER TO SIMULATE THE EROSION WEAR DUE TO SLURRY EROSION}

\begin{abstract}
This paper studies the erosion phenomenon and validation of a slurry pot tester. For this purpose, erosion rates, cumulative weight loss per area and roundness factor were measured. The tests were conducted with 360 CLA brass specimens, by performing four tests with durations of $5,10,15$ and 20 hours, respectively. Samples were weighed on a precision balance before and after testing. The abrasive used was ABNT sand at a concentration of $10 \%$ by weight. Repetitive impacts between the abrasive particles cause cracks and chipping and thus the formation of smaller particles. It was also noted the roundness of the abrasive particles. These facts are the cause of decrease in the erosion rate with increasing test time. Micrographs show the degradation of the surface in front of the specimen due to removal of material. The slurry pot tester succeeded in comparisons with other articles.

Keywords: Slurry pot tester; Slurry erosion; Roundness factor.

1 Engenheiro Mecânico, Faesa, Vitória, Espírito Santo, Brasil.

2 Engenheiro Mecânico, Faesa, Vitória, Espírito Santo, Brasil.

3 Engenheiro Mecânico, Mestre, Professor, Faesa, Vitória, Espirito Santo, Brasil.

4 Engenheiro Mecânico, Mestre, Professor, Faesa, Vitória, Espirito Santo, Brasil.
\end{abstract}




\section{INTRODUÇÃO}

De acordo com Finnie [1], a superfície de um material é atacada por partículas sólidas conduzidas por uma corrente de fluido em muitas aplicações, provocando desgastes nos equipamentos devido à erosão.

Portanto, existe uma necessidade em desenvolver soluções a fim de minimizar seus efeitos. Conforme More, Nandre e Desale [2], o desgaste erosivo é um fenômeno complexo que ainda não é totalmente compreendido devido à existência de muitos fatores que agem simultaneamente, influenciando no processo de erosão.

Desta forma, este trabalho tem como objetivo desenvolver um erosímetro do tipo slurry pot tester para estudos futuros de desgaste erosivo. O equipamento foi validado por meio da comparação de resultados com artigos científicos [3].

Comumente chamado na literatura de slurry pot tester, este erosímetro é muito utilizado para estudar o fenômeno de desgaste por erosão em diversos setores. Ojala, et al. [4] desenvolve em seu estudo um slurry pot tester de alta velocidade para representar o desgaste por erosão que ocorre em materiais que são utilizados em aplicações na indústria de mineração, como no bombeamento de poupa de minério. Já Rajahram, Harvey e Wood [5] utilizam um slurry pot tester modificado para investigar os efeitos de velocidade, tamanho da partícula e sua concentração no fenômeno de erosão-corrosão em um aço inoxidável.

\subsection{Erosão}

Conforme Lynn, Wong e Clark [6], a erosão é essencialmente um processo de remoção de material de uma superfície devido ao impacto repetitivo de partículas transportadas por um gás ou líquido.

\subsection{Taxa de erosão}

De acordo com Clark [7], a taxa de erosão pode ser medida como a perda de massa do material por unidade de área e por unidade de tempo $\left(\mathrm{g} / \mathrm{mm}^{2} . \mathrm{min}\right)$, sendo referido na literatura como $R_{t}$. Esta informação é importante no monitoramento de equipamentos de engenharia em serviço, determinando sua vida útil e planejando sua manutenção.

\subsection{Fator de esfericidade}

Hutchings [8] afirma que o formato das partículas responsáveis pelo desgaste erosivo influenciam fortemente na taxa de desgaste de uma superfície. Geralmente partículas com maior angulosidade possuem maior capacidade de remoção de material em relação às partículas de formado arredondado.

Um dos modelos para se medir a angulosidade de uma partícula foi o fator de esfericidade (F), proposto por Hutchings [8]. Este fator se baseia na medição da área e do perímetro da projeção bidimensional da partícula, geralmente utilizando um microscópio óptico. O fator de esfericidade pode ser definido como a relação entre a área real da projeção da partícula e a área de um círculo com o perímetro igual ao 
da projeção. A fórmula de fator de esfericidade é apresentada por Hutchings [8], conforme Equação (1):

$\mathrm{F}=4 \pi \mathrm{A} / \mathrm{P}^{2}$

Hutchings [8] afirma que se $F=1$, a projeção da partícula é um círculo, e quanto menor for $\mathrm{o}$ valor de $\mathrm{F}$, maior será a angulosidade da partícula, se afastando da forma circular.

\section{MATERIAIS E MÉTODOS}

Os experimentos foram conduzidos em um erosímetro, construído com o objetivo de verificar o comportamento dos corpos de prova sob condições de ensaio préestabelecidos, determinando as perdas de massa, as taxas de erosão, analisando as superfícies erodidas e as partículas abrasivas por meio do uso da microscopia eletrônica de varredura, a fim de comparar resultados obtidos com a literatura, principalmente dos autores Amarendra, Chaudhari e Nath [3]. Sendo assim, foram utilizados condições e parâmetros mais próximos possíveis.

\subsection{Configurações do erosímetro}

O erosímetro utilizado é comumente chamado na literatura de slurry pot tester. É composto por uma furadeira de bancada equipada com um motor de indução trifásico de $1 \mathrm{cv}$ de potência, conforme mostrado na Figura 1 (a). O recipiente utilizado foi de aço inoxidável com capacidade de 12 litros, possuindo um diâmetro de $290 \mathrm{~mm}$ e altura de $182 \mathrm{~mm}$.

O recipiente foi adaptado com quatro chapas verticais de aço inoxidável (baffles), dispostas $90^{\circ}$ uma em relação à outra, com o intuito de minimizar a centrifugação e manter o fluxo turbulento. Também foi projetado e fabricado uma tampa de aço inoxidável, a fim de evitar qualquer tipo de contaminação no experimento, conforme mostrado na Figura 1 (b).

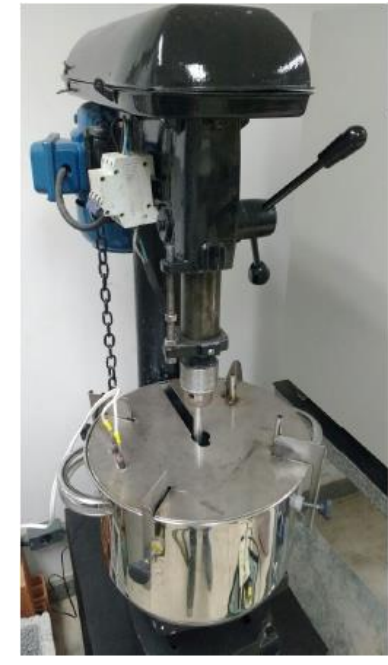

(a)

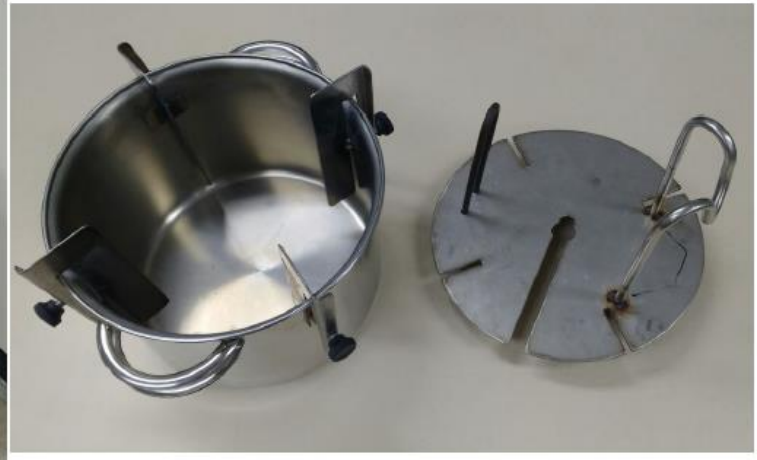

(b)

Figura 1.(a) Visão geral do erosímetro e (b) vista do recipiente e da tampa. 


\subsection{Condições e parâmetros do experimento}

Foram realizados quatro experimentos sob as mesmas condições com as respectivas durações de 5, 10, 15 e 20 horas, parâmetros semelhantes aos apresentados por Amarendra, Chaudhari e Nath [3].

\subsubsection{Corpos de prova}

Os corpos de prova utilizados neste estudo foram de latão 360 Corte Livre Americano (CLA). Foi realizada a usinagem de dezesseis corpos de prova em formato cilíndrico com diâmetro de $15 \mathrm{~mm}$ e altura de $25 \mathrm{~mm}$ de acordo com Amarendra, Chaudhari e Nath [3], conforme Figura 2. Após a usinagem, os corpos de prova foram lixados com lixa 1200.
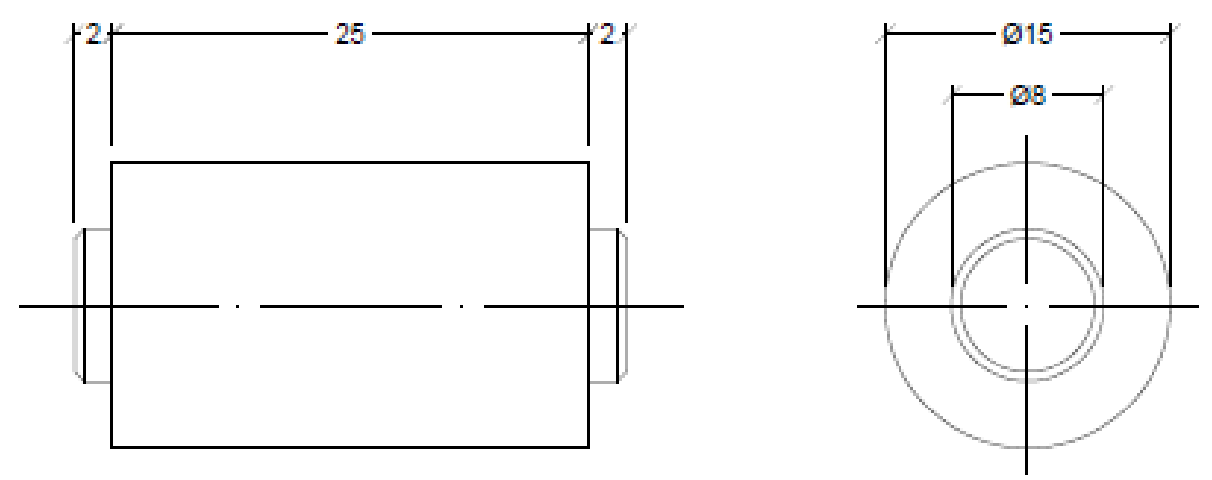

Figura 2.(a) Vista lateral e (b) vista superior.

Foi usinado um pino em cada extremidade do corpo de prova com uma altura de 2 $\mathrm{mm}$ e diâmetro de $8 \mathrm{~mm}$, para a fixação no suporte. Cada corpo de prova foi numerado e marcado na parte superior com um punção para sinalizar a parte frontal no qual o corpo de prova sofrerá maior quantidade de impacto de partículas de acordo com Clark [9], e posteriormente ser analisado.

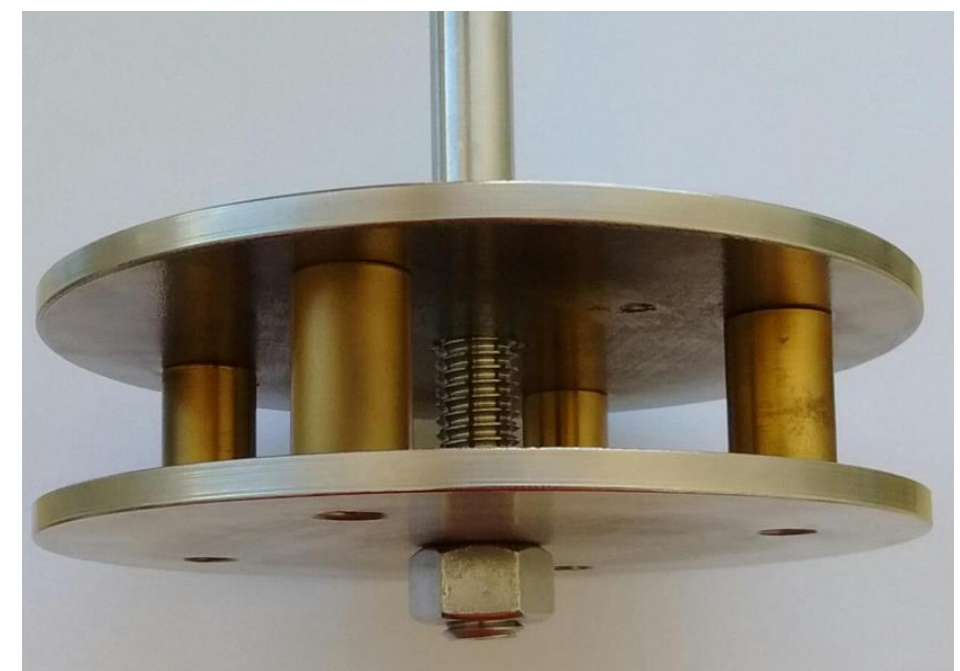

Figura 3.Suporte de fixação dos corpos de prova. 
suporte de fixação dos corpos de prova é formado por um eixo com diâmetro de $12,7 \mathrm{~mm}$ e dois pratos circulares de aço inoxidável. Estes pratos possuem diâmetro de $128 \mathrm{~mm}$, com um furo central de $12,7 \mathrm{~mm}$, espessura de $4 \mathrm{~mm}$ e também quatro furos com diâmetro de $8 \mathrm{~mm}$, dispostos simetricamente com distância de $45 \mathrm{~mm}$ do centro, onde foram fixados os corpos de prova por meio da pressão exercida que foi aplicada nas porcas, conforme Figura 3.

Durante os experimentos, foi desenvolvido um sistema de vedação e isolamento utilizando anéis de borracha e uma película circular de látex para que os corpos de prova não tivessem contato direto com os pratos de aço inoxidável, a fim de evitar efeitos de corrosão galvânica, conforme Amarendra, Chaudhari e Nath [3] e garantindo que o desgaste ocorresse somente na área lateral.

\subsubsection{Abrasivo}

O abrasivo utilizado no experimento foi a areia normal brasileira fornecida pelo Instituto de Pesquisas Tecnológicas (IPT) segundo norma da Associação Brasileira de Normas Técnicas NBR 7214:2015 [10], possuindo granulometria entre $150 \mu \mathrm{m}$ e $300 \mu \mathrm{m}$. Foi utilizada uma concentração de $10 \%$ em peso conforme Amarendra, Chaudhari e Nath [3], sendo 8 litros de água destilada e 800 gramas do abrasivo. A temperatura do fluido durante o experimento foi monitorada, apresentando um valor aproximado de $30^{\circ} \mathrm{C}$.

\subsubsection{Velocidade de teste}

A rotação utilizada durante os experimentos foi de $1004 \mathrm{rpm}$ correspondendo a uma velocidade linear e de impacto de aproximadamente $4,7 \mathrm{~m} / \mathrm{s}$ da areia contra a superfície do corpo de prova.

\subsection{Procedimentos de limpeza e pesagem}

Foi realizado um procedimento de limpeza dos corpos de prova antes e depois do experimento, conforme Carvalho [11]. Inicialmente foram lavados em água corrente. Após a lavagem, eles foram imersos em um banho de álcool com o auxílio do ultrassom, a fim de remover as impurezas da superfície. Em seguida, foi realizada a secagem dos corpos de prova com ar quente. Para a manipulação dos corpos de prova, luvas foram utilizadas para evitar qualquer tipo de contaminação que possa influenciar nas pesagens e análises da superfície erodida. Após a limpeza, os corpos de prova foram encaminhados para as pesagens. As taxas de erosão foram determinadas pela diferença de peso antes e depois do experimento, utilizando uma balança analítica com resolução de $0,1 \mathrm{mg}$.

\section{RESULTADOS E DISCUSSÃO}

\subsection{Perdas de massa}

A fim de mostrar a evolução da degradação dos corpos de prova, foram efetuados quatro experimentos com durações de 5, 10, 15 e 20 horas. A Figura 4 apresenta a perda de massa por unidade de área $\left(\mathrm{g} / \mathrm{mm}^{2}\right)$. Quanto maior o tempo de exposição do corpo de prova ao meio erosivo, maior foi sua perda de massa acumulada. 


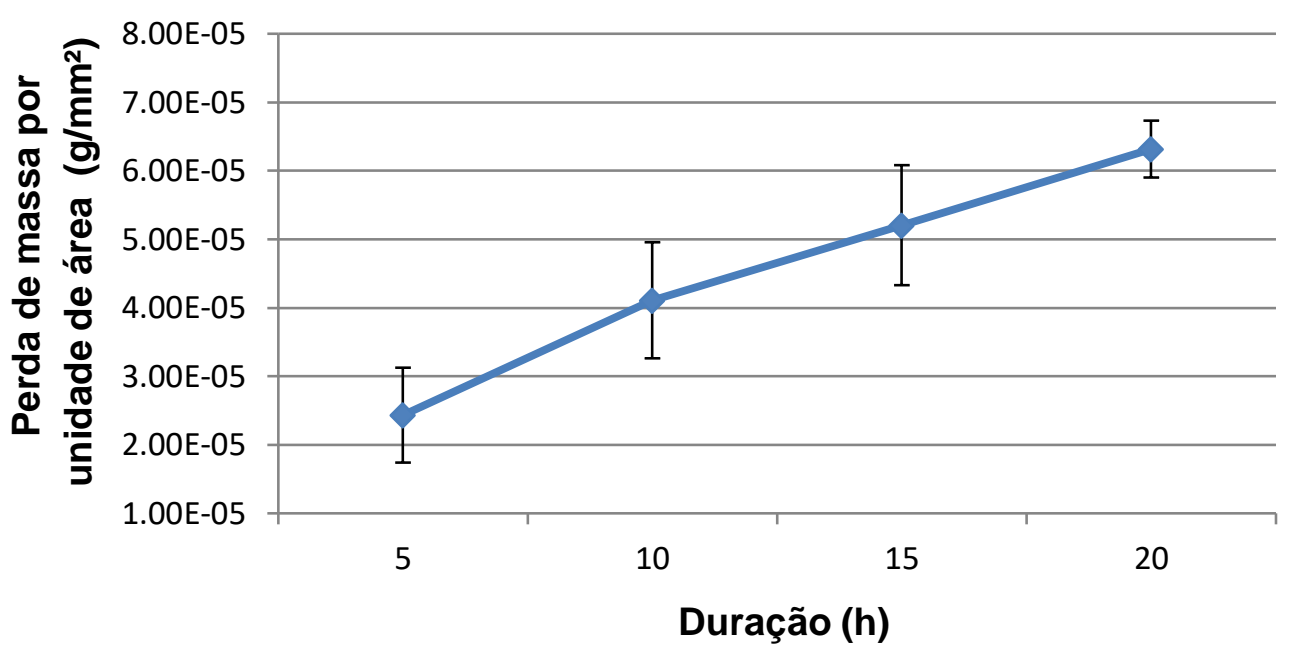

Figura 4.Perda de massa por unidade de área

Comparando os resultados obtidos com o gráfico dos autores Amarendra, Chaudhari e Nath [3], conforme mostrado na Figura 5, podem-se observar valores próximos de perda de massa por unidade de área em função do tempo. Na Figura 5, esta perda de massa é representada com a identificação de "without cavitation inducer".

Fonte: AMARENDRA; CHAUDHARI; NATH, 2012.

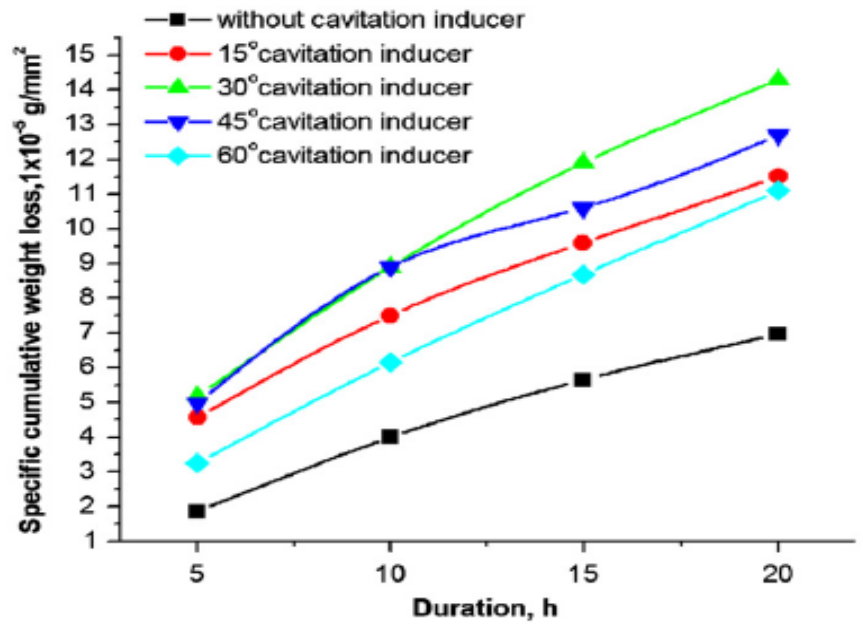

Figura 5.Perda de massa por unidade de área para corpos de prova em latão testados em meio lamacento.

Pelos valores obtidos na Figura 4, pode-se observar um comportamento curvilíneo para a perda de massa por unidade de área em função do tempo. Este comportamento é verificado em outros artigos acadêmicos, conforme apresentado por Amarendra, Chaudhari e Nath [3] e Kishor, Chaudhari e Nath [12].

A queda da inclinação da curva ao longo do tempo pode ser atribuída devido aos contatos e choques que ocorrem entre as partículas abrasivas dentro do recipiente, fazendo com que a capacidade de remover material da superfície seja reduzida ao longo do tempo, e consequentemente, diminuindo sua taxa de erosão conforme explicado por Clark [7]. 
A forma das partículas abrasivas é alterada devido aos impactos que elas sofrem durante o experimento, o que diminui sua angulosidade, adquirindo uma forma mais arredondada e exibindo um decréscimo em sua taxa de desgaste por erosão, conforme apresentado na Figura 6 e observado por Clark [7].

O aspecto curvilíneo da perda de massa por unidade de área (Figura 4) e o decréscimo da taxa de erosão (Figura 6) podem ser explicados em grande parte devido ao arredondamento e diminuição do tamanho das partículas abrasivas. Resultados semelhantes foram obtidos por Lynn, Wong e Clark [6], Carvalho [11] e Clark [7].

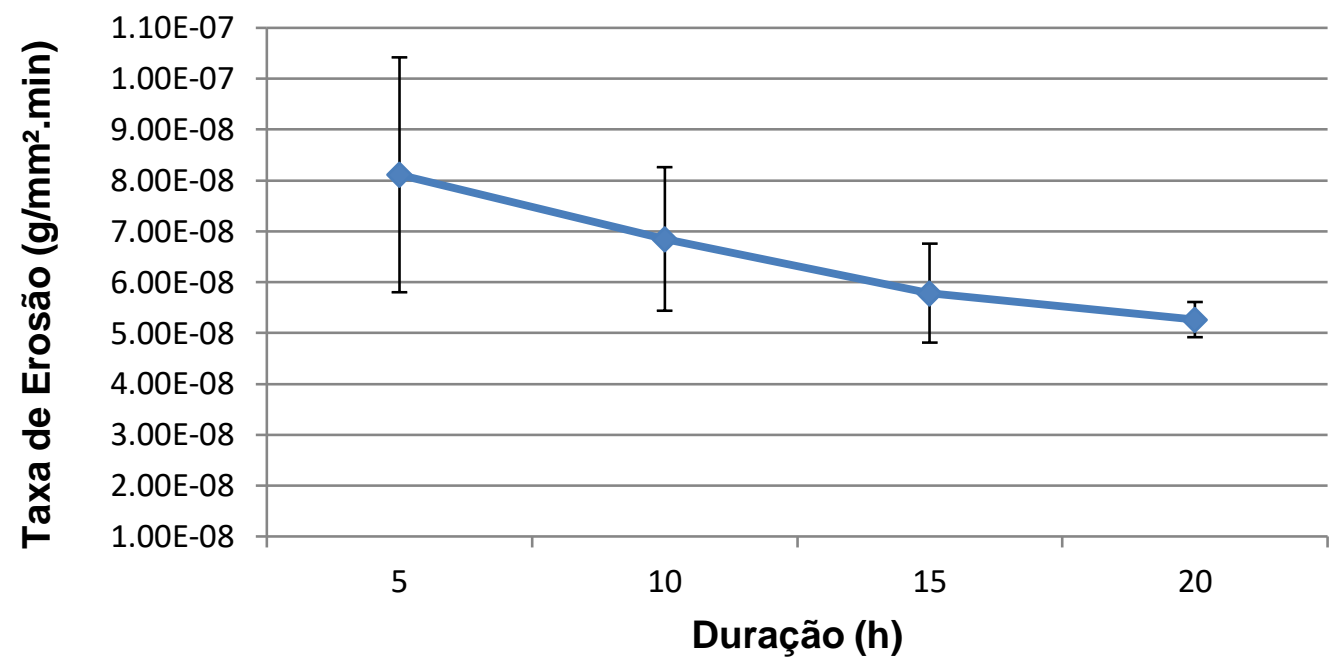

Figura 6.Taxa de erosão

\subsection{Fator de esfericidade e tamanho da partícula}

A fim de se avaliar este parâmetro, foram coletadas amostras da areia como recebida e após experimento de 20 horas e foram analisadas no microscópio de varredura eletrônica. Suas respectivas micrografias são apresentadas na Figura 7.

Pela análise das micrografias obtidas, foi observada a variação da forma das partículas por meio do cálculo do fator de esfericidade com o software de domínio público ImageJ, cujo resultado é mostrado na Tabela 1.

Tabela 1.Fator de esfericidade da areia como recebida e após o experimento de 20 horas.

\begin{tabular}{|c|c|}
\hline \multicolumn{2}{|c|}{ Fator de esfericidade (F) } \\
\hline Areia como recebida & 0,449522 \\
\hline Areia após experimento de 20 horas & 0,498236 \\
\hline
\end{tabular}


Pode-se observar que as partículas de areia sofreram um aumento em seu fator de esfericidade, confirmando seu arredondamento devido aos repetitivos impactos durante o experimento.

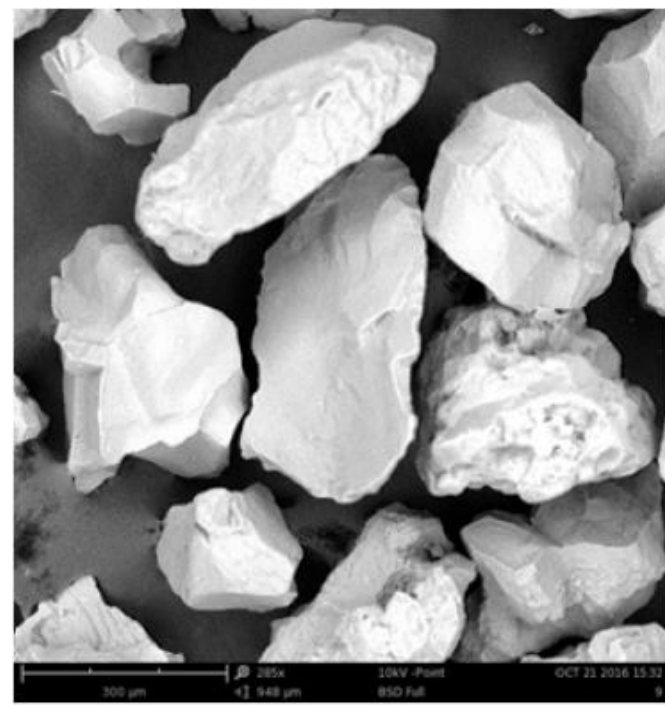

(a)

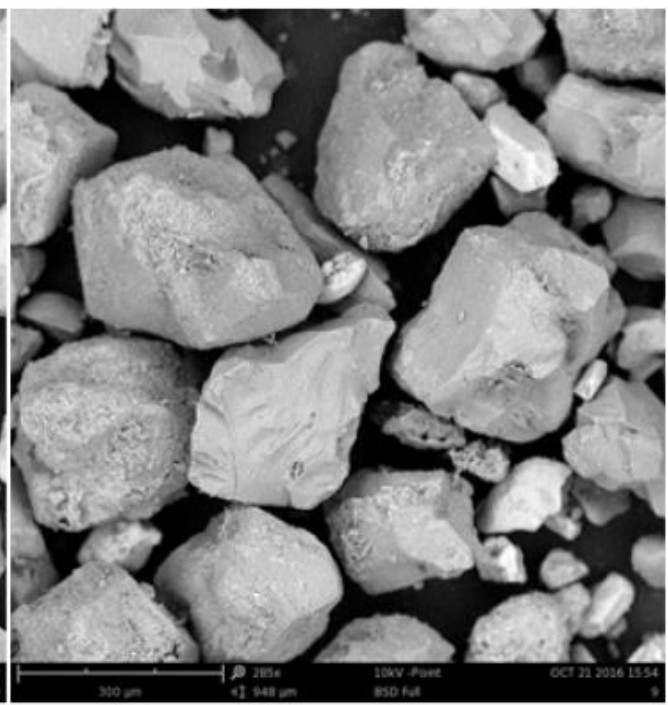

(b)

Figura 7.Partícula de areia (a) como recebida e (b) após o experimento de 20 horas.

$\mathrm{Na}$ Figura 8 pode-se observar que depois do experimento, as partículas abrasivas apresentaram trincas e lascamentos, criando partículas menores que podem ser vistas na micrografia. Pode-se dizer que outro fator que influenciou no decréscimo da taxa de erosão foi devido ao impacto de particulados menores que, de acordo com Lynn, Wong e Clark [6], causam menor desgaste na superfície.

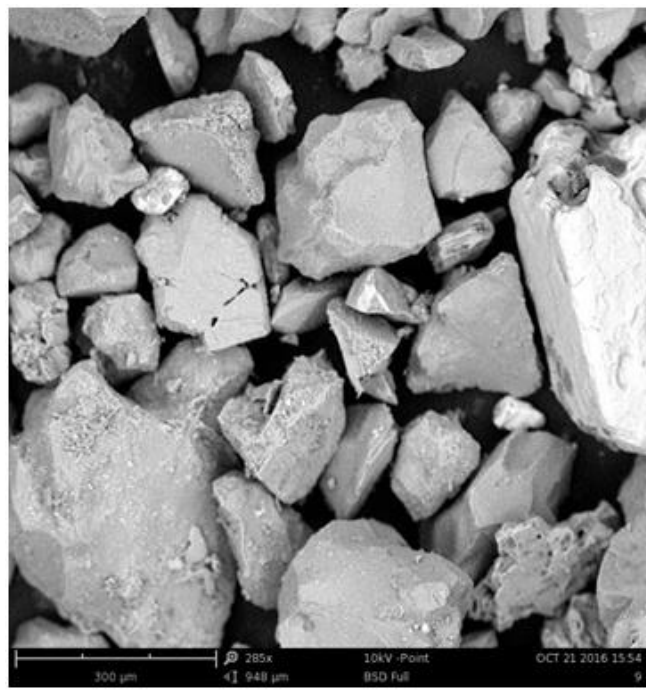

(a)

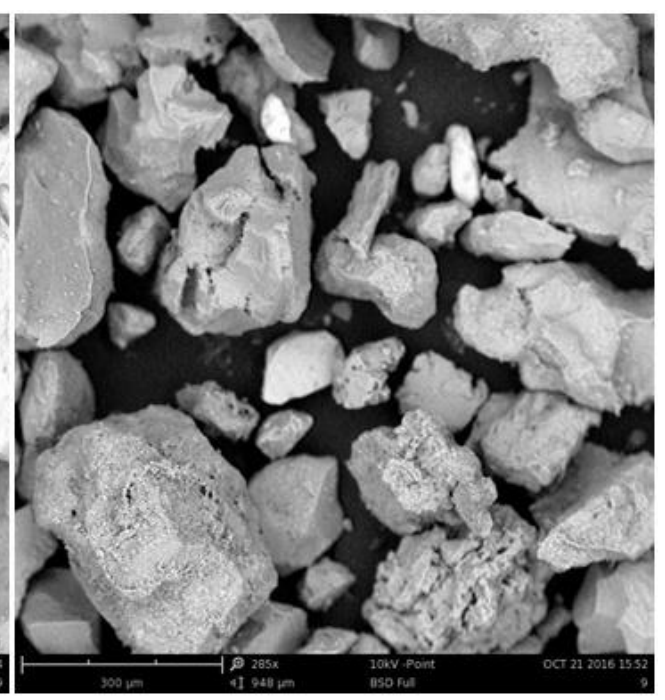

(b)

Figura 8.Partículas de areia após experimento de 20 horas, com detalhe para os lascamentos, trincas e partículas menores lascadas.

Carvalho [11] apud Wong e Clark (1993) explica a existência de um filme superficial formado pelo fluido sobre o corpo de prova. Este filme superficial reduziria a 
velocidade de impacto ou até evitaria a colisão das partículas, principalmente das menores, que possuem pouca energia cinética devido às suas pequenas massas.

Lynn, Wong e Clark [6] observam a influência do tamanho da partícula apresentando um gráfico obtido por meio de experimentos em um slurry pot tester, comparando este fator com a taxa de erosão, conforme pode ser analisado na Figura 9. Pode-se observar que partículas maiores apresentaram maiores taxas de erosão.

Fonte: LYNN; WONG; CLARK, 1991.

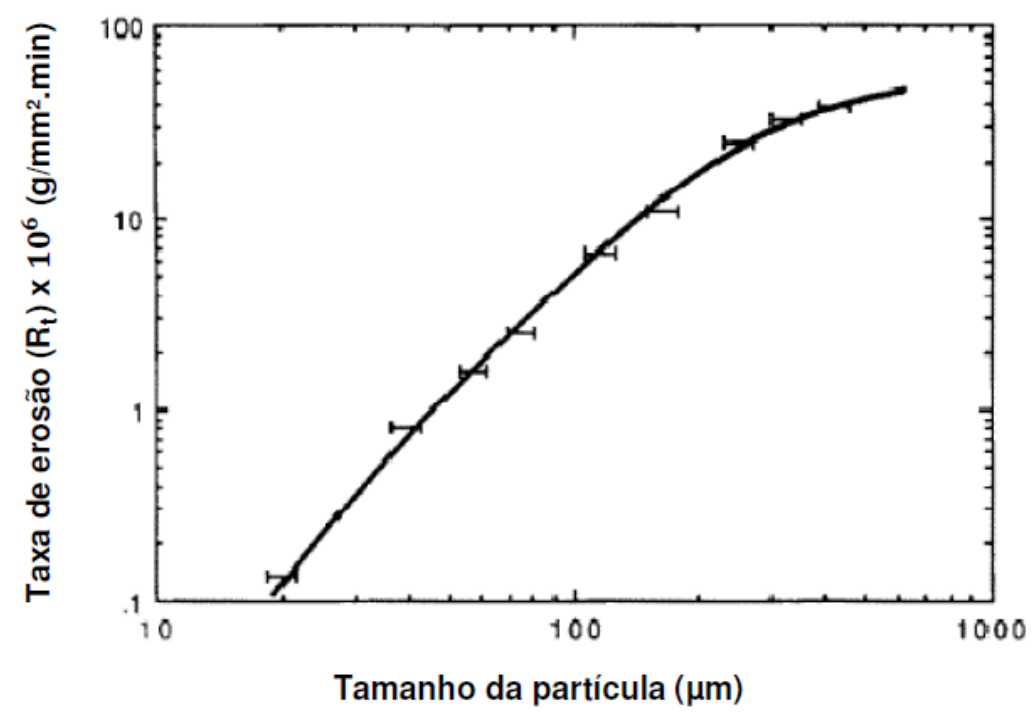

Figura 9.Taxa de erosão de um aço P110, para uma concentração de 1,2\% em peso de SiC para diferentes tamanhos de partículas, ensaiados em óleo diesel à uma velocidade nominal de $18,7 \mathrm{~m} / \mathrm{s}$.

Outro fator que pode influenciar a menor taxa de erosão para as partículas pequenas é o encruamento, que ocorre devido aos impactos e deformações plásticas, formando uma camada superficial com maior dureza em relação ao material base. De acordo com Misra e Finnie [13], enquanto as partículas menores colidem apenas com a camada superficial endurecida, as partículas maiores também atingem o material abaixo desta camada, causando maior desgaste.

Com estes resultados, pode-se confirmar a influência do tamanho, forma da partícula e seu fator de esfericidade no desgaste por erosão, conforme apresentado por Hutchings [8].

\subsection{Análise da superfície}

Foram separadas amostras das superfícies frontais dos corpos de prova como recebido e após os experimentos de 5, 10, 15 e 20 horas e analisadas no microscópio eletrônico de varredura. A identificação da área frontal foi possível devido à marcação com o punção realizada anteriormente. A superfície frontal do corpo de prova cilíndrico é a área que sofrerá maior quantidade de impacto de partículas, sendo a região mais agredida, conforme apresentado por Clark [9].

A Figura 10 mostra uma micrografia feita em um microscópio eletrônico de varredura da superfície frontal do corpo de prova, lixada antes do experimento. Podem-se 
observar ranhuras na superfície que podem ser atribuídos ao processo de lixamento dado aos corpos de prova.

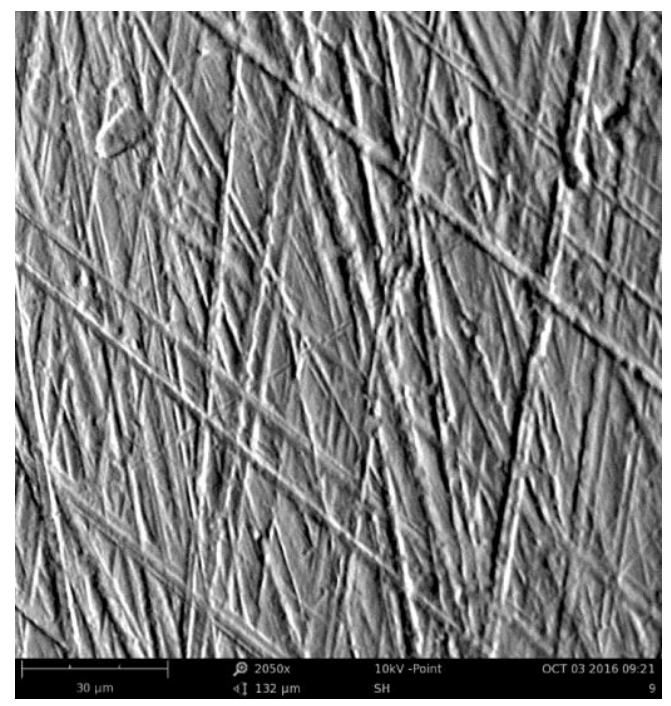

Figura 10.Aspecto da superfície frontal do corpo de prova de latão 360 CLA, após o lixamento.

A Figura 11 mostra uma micrografia realizada em um microscópio eletrônico de varredura da superfície frontal do corpo de prova após os testes de 5, 10, 15 e 20 horas. A erosão observada foi causada pelas partículas de areia em suspensão presentes na água, deformando e removendo material do corpo de prova. Pode-se obsevar que as ranhuras que foram identificadas anteriormente na superfície devido ao processo de lixamento sumiram.

As micrografias obtidas na Figura 11 caracterizam a evolução do desgaste erosivo na superfície do corpo de prova, causado pelos repetitivos impactos das partículas abrasivas. Resultados similares também foram encontrados por Amarendra, Chaudhari e Nath [3].

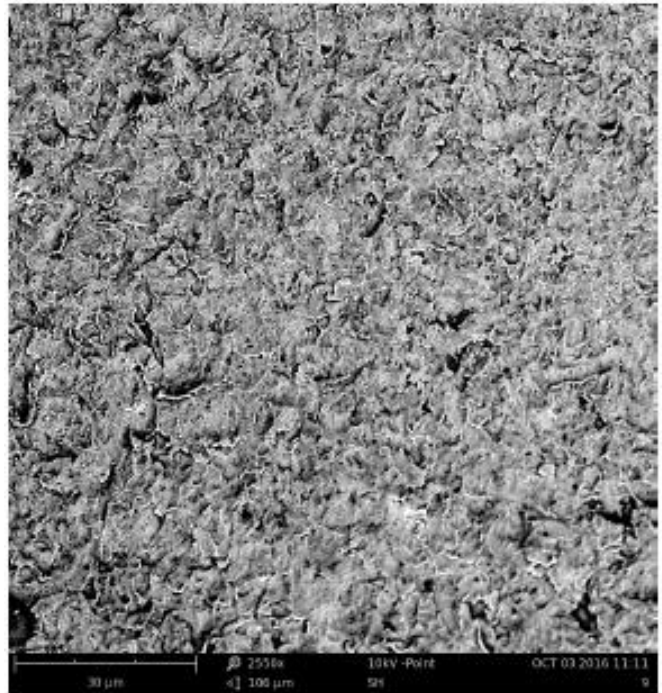

(a)

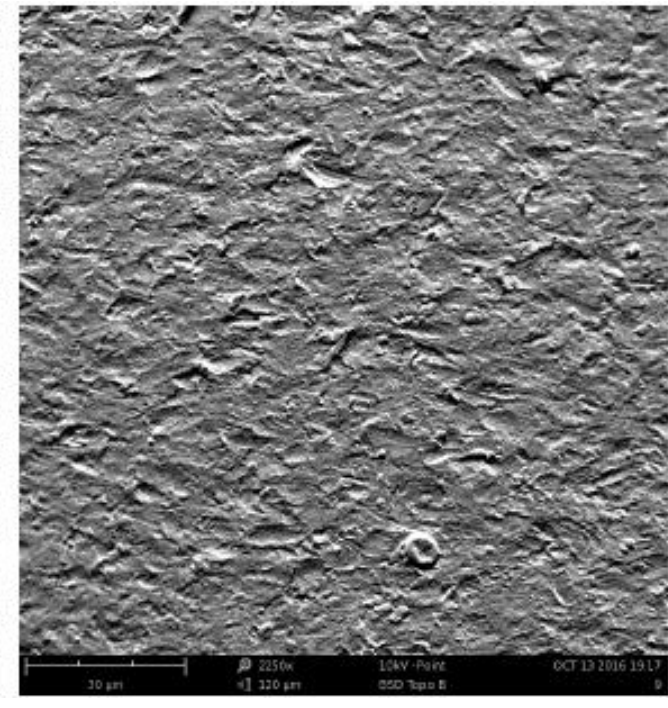

(b) 


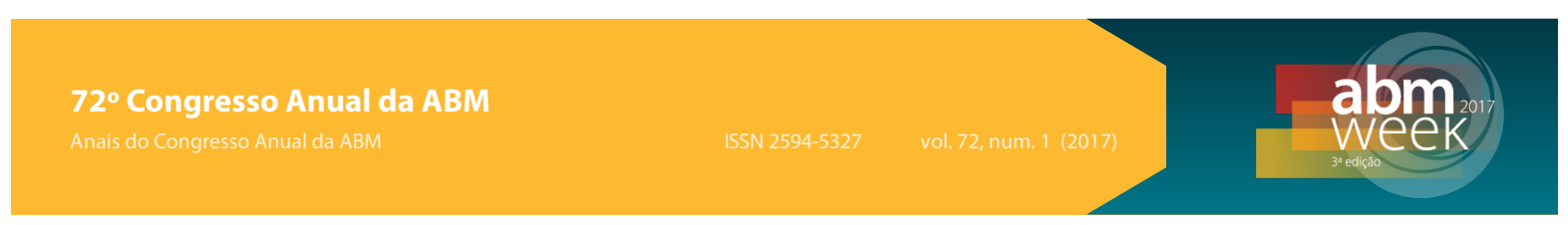

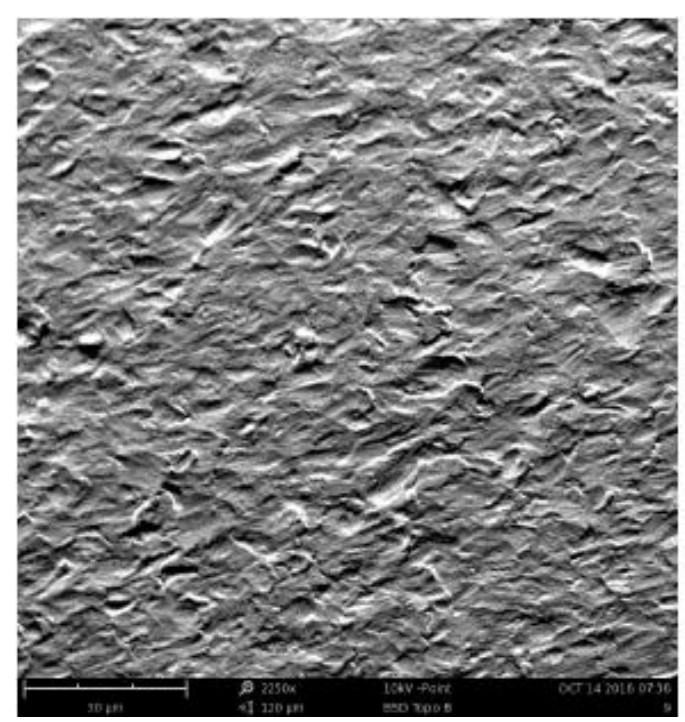

(c)

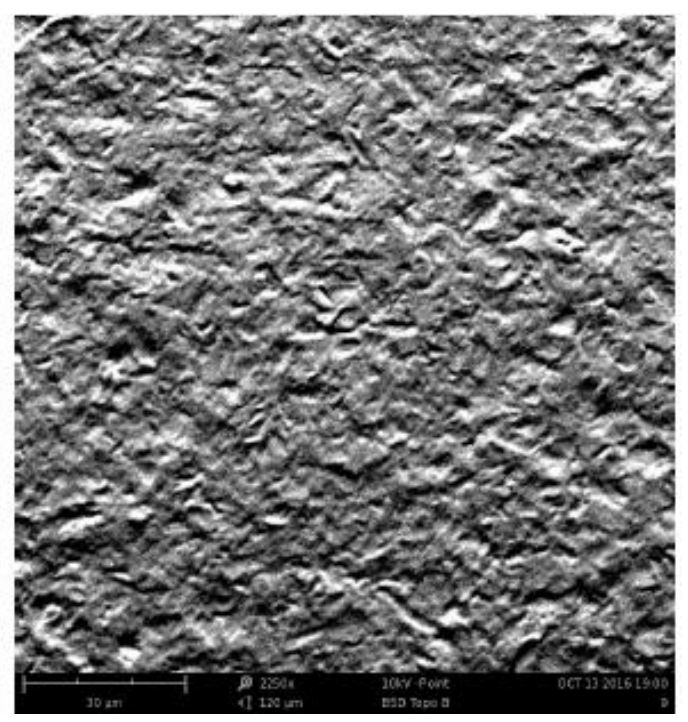

(d)

Figura 11. Aspecto da superfície frontal dos corpos de prova de latão $360 \mathrm{CLA}$, após o experimento de (a) 5 horas, (b) 10 horas, (c) 15 horas e (d) 20 horas.

\section{CONCLUSÃO}

Os resultados obtidos de perda de massa, taxa de erosão, análises das superfícies erodidas e das partículas abrasivas no microscópio eletrônico de varredura e óptico, indicam que o erosímetro desenvolvido obteve sucesso nas comparações com artigos internacionais, principalmente de Amarendra, Chaudhari e Nath [3], comprovando que o equipamento pode ser utilizado em estudos futuros sobre 0 desgaste erosivo.

A perda de massa em função do tempo seguiu um padrão crescente com o decorrer do experimento, porém, apresentou um aspecto curvilíneo, também encontrado em outros trabalhos, como Clark [7], indicando a influência do arredondamento das partículas devido aos repetitivos impactos, diminuindo sua capacidade de remover material da superfície do corpo de prova. A taxa de erosão apresentou um decréscimo com o decorrer do experimento, no qual também pode ser atribuído ao arredondamento das partículas, sendo que seu fator de esfericidade apresentou uma forma mais esférica após o ensaio.

Outro fator que pode influenciar no aspecto curvilíneo da perda de massa e no decréscimo da taxa de erosão em função do tempo, é a presença de partículas menores provenientes de lascamentos do abrasivo conforme observado no microscópio eletrônico de varredura. De acordo com Lynn, Wong e Clark [6], partículas menores apresentam menores taxas de erosão.

\section{REFERÊNCIAS}

[1] Finnie I, Erosion of surfaces by solid particles. Wear. 1960; (3): 87-103.

[2] More SR, Nandre BD, Desale GR. Development of Pot Tester to Simulate the Erosion Wear due to Solid-Liquid Mixture. International Journal of Researchers, Scientists and Developers. 2014; (2): 6-12. 
[3] Amarendra HJ, Chaudhari GP, Nath SK. Synergy of cavitation and slurry erosion in the slurry pot tester. Wear. 2012; (290-291): 25-31.

[4] Ojala N, Valtonen K, Kivikyto"-Reponen P, Vuorinen P, Siitonen P, Kuokkala V.-T. Effect of test parameters on large particle high speed slurry erosion testing. Tribology - Materials, Surfaces \& Interfaces. 2014; (8:2): 98-104.

[5] Rajahram SS, Harvey TJ, Wood RJK. Electrochemical investigation of erosioncorrosion using a slurry pot erosion tester. Tribology International. 2011; (44): 232240.

[6] Lynn RS, Wong KK, Clark HMcl. On the particle size effect in slurry erosion. Wear. 1991; (149): 55-71.

[7] Clark HMcl. A comparison of the erosion rate casing steels by sand-oil suspensions. Wear. 1991; (151): 217-230.

[8] Hutchings IM. Tribology - Friction and Wear of Engineering Materials. London: Edward Arnold; 1992.

[9] Clark HMcl. Particle velocity and size effects in laboratory slurry erosion measurements OR... do you know what your particles are doing? Tribology International. 2002; (35): 617-624

[10] Associação brasileira de Normas Técnicas. NBR 7214: Areia normal para ensaio de cimento - Especificação. Rio de Janeiro: ABNT, 2015.

[11] Carvalho EB. Corrosão-erosão de aço para tubo de revestimento em meio contendo $\mathrm{H}_{2} \mathrm{~S}$. [Dissertação de Mestrado]. Vitória: Universidade Federal do Espírito Santo, Programa de Pós Graduação Engenharia Mecânica; 2004.

[12] Kishor B, Chaudhari GP, Nath SK. Slurry erosion of thermo-mechanically processed 13Cr4Ni stainless steel. Tribology International. 2016; (93): 50-57.

[13] Misra A, Finnie I. On the size effect in abrasive and erosive wear. Wear, 1981: (65): 359-373. 